\title{
Adsorption of Copper at Aqueous Illite Surfaces
}

\author{
Qing Du, $* \dagger$ ZhongXi Sun, $*$ Willis Forsling, ${ }^{*}, 1$ and HongXiao Tang $\dagger$ \\ * Division of Inorganic Chemistry, Luleå University of Technology, S-971 87 Luleå, Sweden; and \\ $\dagger$ Research Center for Eco-Environmental Sciences, Academia Sinica, 100085 Beijing, China
}

Received August 2, 1996; accepted October 31, 1996

In this paper, we conducted potentiometric titrations, batch adsorption experiments and FT-IR analysis to study the uptake of copper in illite/water suspensions and then applied the constant capacitance surface complexation model to interpret the reaction mechanism at the aqueous illite surfaces. Our research shows that the copper adsorption at these surfaces is strongly dependent on $\mathrm{pH}$ and that the adsorption causes a deprotonation of surface groups. We propose that the uptake of copper in the carbonatefree illite suspensions can be explained by the formation of mononuclear surface complexes, $\equiv \mathrm{SOCu}^{+}$and $\equiv \mathrm{SOCuOH}$, and a multinuclear surface complex, $\equiv \mathrm{SOCu}_{2}(\mathrm{OH})_{2}^{+}$, followed by the formation of a bulk precipitate, $\mathrm{Cu}(\mathrm{OH})_{2}(\mathrm{~s})$, or a surface precipitate, $\equiv \mathrm{SOCu}_{2}(\mathrm{OH})_{3}(\mathrm{sp})$. For the illite suspensions containing carbonates, we propose that the copper-illite interaction can be depicted by the formation of mononuclear surface complexes, $\equiv \mathrm{SOC} \mathrm{u^{+ }}$ and $\equiv \mathrm{SOC} \mathrm{uOH}$, followed by the formation of a copper hydroxylcarbonate precipitate, $\mathrm{Cu}_{2}(\mathrm{OH})_{2} \mathrm{CO}_{3}(\mathrm{~s})$, rather than a copper hydroxide precipitate. The existence of $\mathrm{Cu}_{2}(\mathrm{OH})_{2} \mathrm{CO}_{3}(\mathrm{~s})$ in the carbonate-containing illite suspensions was identified by FT-IR analysis. 1997 Academic Press

Key Words: illite; copper adsorption; potentiometric titrations; FT-IR analysis; constant capacitance model.

\section{INTRODUCTION}

Sediments in natural water systems act both as sinks and sources of heavy metal contaminants. Under certain environmental conditions, heavy metals are sorbed by waterborne suspended materials and then deposited in bottom sediments via processes such as coagulation and precipitation. Water quality is thereby improved as heavy metal ions are transferred from water into sediments. Under different conditions, the pollutants sorbed on sediments are released back into the water system, thus causing re-deterioration of water quality. In this cycle most of the significant physicochemical reactions are those at the sediment/water interface. Therefore, in order to effectively evaluate the pollution status and potential ecological impacts of heavy metals on aquatic ecosystems, it is important to study the reaction mechanisms at sediment/water interfaces.

\footnotetext{
${ }^{1}$ To whom correspondence should be addressed.
}

Sediments are primarily made up of clay minerals, which are sheet silicates constructed of tetrahedral sheets ( silica tetrahedra, $\mathrm{SiO}_{4}$ ) and octahedral sheets (gibbsite structure, $\left.\gamma-\mathrm{Al}(\mathrm{OH})_{3}\right)$. The three most common clay minerals in soil systems are kaolinite, montmorillonite, and illite.

The adsorption of heavy metals at the kaolinite/water and montmorillonite/water interfaces has been studied by Schindler and Stadler et al. using the constant capacitance surface complexation model $(1,2)$. They account for the surface adsorption behavior of kaolinite and montmorillonite by postulating a combined ion exchange-surface complexation model that assumes two kinds of binding sites on the clay mineral surfaces: (a) weakly acidic groups ( $\equiv \mathrm{XH})$, which undergo ion exchange, and (b) amphoteric surface hydroxyl groups $(\equiv \mathrm{SOH})$, which form inner sphere complexes with heavy metal ions. A similar two-step adsorption mechanism on kaolinite surfaces has also been suggested by Spark et al. (3), who studied the adsorption of trace metals as a function of $\mathrm{pH}$, the concentration of the substrate, and the nature and concentration of the supporting electrolyte. They found that the uptake of all the studied heavy metals ( Cu(II), Zn(II), Co(II), and Cd(II)) showed clear evidence of two distinct adsorption processes: Type 1 adsorption (the first stage), which occurred on the permanent negatively charged siloxanol sites, and Type 2 adsorption (the second stage), which had characteristics similar to the adsorption on alumina, indicating that this process occurred on the variable-charged aluminol sites.

Illites occupy half or more of the clay minerals in the earth's crust. The chemisorption of $\mathrm{Cu}$ (II) onto the surface of muscovite mica (which has the same structure and composition as illite) has been demonstrated by studies using reflection extended X-ray absorption fine structure spectroscopy (REFLEXAFS) and X-ray photoelectron spectroscopy (XPS) (4). XPS studies suggest that the $\mathrm{Cu}$ species is in a bonding environment similar to that of copper in copper hydroxide. REFLEXAFS studies provide direct evidence that $\mathrm{Cu}$ is bound to the surface at aluminate or silicate groups and they also suggest that the $\mathrm{Cu}$ species adsorbed onto the surface are similar to the copper species found in copper hydroxide, plancheite $\left(\mathrm{Cu}_{8}\left(\mathrm{Si}_{4} \mathrm{O}_{11}\right)_{2}(\mathrm{OH})_{4}\left(\mathrm{H}_{2} \mathrm{O}\right)\right)$ and shat- 
TABLE 1

Surface Characteristics of an Illite/W ater System (Particle Size, $<63 \mu$, Illite $=5 \mathrm{~g} /$ liter, $I=0.1 \mathrm{M} \mathrm{NaN} \mathrm{O}_{3}, 2^{\circ} \mathrm{C}$ )

\begin{tabular}{|c|c|c|c|}
\hline \multicolumn{4}{|c|}{ Illite suspension } \\
\hline Surface proton reaction & $\equiv \mathrm{SOH} \rightleftarrows \equiv \mathrm{SO}^{-}+\mathrm{H}^{+}$ & Intrinsic surface acidic constant $\mathrm{p} K_{\mathrm{a}}^{\text {int }}$ & 4.23 \\
\hline Specific constant capacitance $C\left(\mathrm{Fm}^{-2}\right)$ & 1.7 & $\mathrm{~N}_{2} / \mathrm{BET}$ surface area $S\left(\mathrm{~m}^{2} \mathrm{~g}^{-1}\right)$ & 22.3 \\
\hline Total proton surface sites $\mathrm{H}_{\mathrm{S}}(\mathrm{mmol} / \mathrm{L})$ & 0.642 & Surface site density (sites $\mathrm{nm}^{-2}$ ) & 3.5 \\
\hline \multicolumn{4}{|c|}{ Corresponding supernatant blank } \\
\hline $\begin{array}{l}\text { Total concentration of } \mathrm{Al}\left(\mathrm{H}_{2} \mathrm{O}\right)_{6}^{3+}(\mathrm{mmol} / \text { liter }) \\
\text { Proton reactions of } \mathrm{Al}\left(\mathrm{H}_{2} \mathrm{O}\right)_{6}^{3+a}\end{array}$ & & \multicolumn{2}{|c|}{$\begin{array}{l}0.0246 \\
\mathrm{Al}\left(\mathrm{H}_{2} \mathrm{O}\right)_{6}^{3+}+\mathrm{OH}^{-} \rightleftarrows \mathrm{Al}\left(\mathrm{H}_{2} \mathrm{O}\right)_{6} \mathrm{OH}^{2+}, \log K=8.48\left(25^{\circ} \mathrm{C}, I=0.1\right) \\
\mathrm{Al}\left(\mathrm{H}_{2} \mathrm{O}\right)_{6}^{3+}+2 \mathrm{OH}^{-} \rightleftarrows \mathrm{Al}\left(\mathrm{H}_{2} \mathrm{O}\right)_{6}(\mathrm{OH})_{2}^{+}, \log K=17.6\left(25^{\circ} \mathrm{C}, I=\right. \\
0.1)\end{array}$} \\
\hline $\begin{array}{l}\text { Total concentration of } \mathrm{Si}(\mathrm{OH})_{4}(\mathrm{mmol} / \mathrm{liter}) \\
\text { Proton reactions of } \mathrm{Si}(\mathrm{OH})_{4}{ }^{a}\end{array}$ & & \multicolumn{2}{|c|}{$\begin{array}{l}\mathrm{Si}(\mathrm{OH})_{4} \rightleftarrows \mathrm{SiO}(\mathrm{OH})_{3}^{-}+\mathrm{H}^{+}, \log K=-9.46\left(25^{\circ} \mathrm{C}, I=0.5\right) \\
\mathrm{SiO}(\mathrm{OH})_{3}^{-} \rightleftarrows \mathrm{SiO}_{2}(\mathrm{OH})_{2}^{2-}+\mathrm{H}^{+}, \log K=-12.56\left(25^{\circ} \mathrm{C}, I=0.5\right)\end{array}$} \\
\hline
\end{tabular}

${ }^{a}$ The acidic constants of $\mathrm{Al}\left(\mathrm{H}_{2} \mathrm{O}\right)_{6}^{3+}$ and $\mathrm{Si}(\mathrm{OH})_{4}$ in water solutions are taken from ref (6).

tuckite $\left(\mathrm{Cu}_{5}\left(\mathrm{SiO}_{3}\right)_{4}(\mathrm{OH})_{2}\right)$. Nevertheless, few sophisticated theoretical models have been proposed to illustrate the adsorption mechanisms of heavy metal ions at aqueous illite surfaces.

In our research, we extended the constant capacitance surface complexation model to explain the reaction mechanisms at the illite/water interfaces. In a previous paper, we report the results of a study on the acid-base properties of aqueous illite surfaces (5). From these results, we conclude that the acid-base behavior at the illite/water interface can be well described by one deprotonation reaction of the amphoteric surface hydroxyl groups,

$$
\equiv \mathrm{SOH} \rightleftarrows \equiv \mathrm{SO}^{-}+\mathrm{H}^{+}, K_{\mathrm{a}}^{\mathrm{int}}
$$

and that the proton reactions in the supernatants of the illite suspensions can be represented by the proton reactions of $\mathrm{Al}\left(\mathrm{H}_{2} \mathrm{O}\right)_{6}^{3+}$ and $\mathrm{Si}(\mathrm{OH})_{4}$ in water solutions (Table 1). In the present paper, we focus on studying the adsorption of heavy metal $\mathrm{Cu}$ (II) at the illite surfaces and establishing a copper-illite interaction model to interpret the uptake of copper in the illite/water suspensions.

\section{MATERIALS AND METHODS}

\section{Materials}

The sample of illite used in our experiments was obtained from Hebei Province, China. It was prepared by being ground and passed through a sieve of 240 mesh $(63 \mu \mathrm{m})$. Two weeks prior to the experiments, a stock suspension of $10 \mathrm{~g} /$ liter illite was made and then stored in a refrigerator. The main composition of this sample is given in detail in another paper (5) and its surface characteristic parameters are given in Table 1.
Diluted $\mathrm{HNO}_{3}$ solution was standardized against tris(hydroxymethyl) aminomethane (THAM). $\mathrm{NaOH}$ solution was prepared from BDH concentrated solutions and standardized using an acid of known concentration. $\mathrm{Cu}\left(\mathrm{NO}_{3}\right)_{2}$ (Orion Cat. No. 942906) at a concentration of $0.1000 \mathrm{M}$ was used as the standard copper stock solution. Concentrated sodium nitrate solution was used to maintain various ionic strengths. For recording the standard infrared spectra of pure $\mathrm{Cu}(\mathrm{OH})_{2}$ and $\mathrm{Cu}_{2}(\mathrm{OH})_{2} \mathrm{CO}_{3}$ by FT-IR analysis, copper hydroxide (1.5895, KEBO-Lab) and copper hydroxylcarbonate (1.2799, KEBO-Lab) were used.

\section{Apparatus}

An automatic system for precise emf titrations constructed by Ginstrup (7) was used to perform potentiometric titrations. The cell arrangement, similar to that described by Forsling et al. (8), was immersed in an oil thermostat at $25.0 \pm 0.5^{\circ} \mathrm{C}$. A double junction $\mathrm{Ag} / \mathrm{AgCl}$ electrode (Orion 90-02) was used as a reference electrode. A glass electrode (Ingold type 201-NS) and a cupric selective electrode were used for the $\mathrm{H}^{+}$and $\mathrm{Cu}^{2+}$ measurements, respectively.

PE3100 flame atomic absorption spectrometer (AAS) was used to determine the copper concentration in the batch adsorption experiments.

A single beam PE2000 FT-IR spectrometer was used to record the infrared spectra. The DRIFT spectra were taken at a resolution of $4 \mathrm{~cm}^{-1}$ by co-adding up to 200 scans in the range $4000-400 \mathrm{~cm}^{-1}$ using a diffuse reflectance method. For each measurement, the sample was prepared by mixing $1 \mathrm{mg}$ sample with $100 \mathrm{mg}$ finely ground $\mathrm{KBr}$; pure $\mathrm{KBr}$ powder was used as a reference.

\section{Potentiometric Titrations}

Three illite suspensions with $5 \mathrm{~g} /$ liter illite and $0.1 \mathrm{M}$ $\mathrm{NaNO}_{3}$ but different initial copper concentrations $(0.105$, 
0.184 , and $0.544 \mathrm{mM} \mathrm{Cu}{ }^{2+}$ ) were titrated using the procedures given below.

First, $25 \mathrm{ml}$ of $10 \mathrm{~g} /$ liter illite stock suspension and $5 \mathrm{ml}$ of $1 \mathrm{M} \mathrm{NaNO}_{3}$ was added to a $100 \mathrm{ml}$ flask. Distilled water was added to bring the total initial volume of the suspension to $50 \mathrm{ml}$. $\mathrm{N}_{2}$ was bubbled successively through $10 \% \mathrm{NaOH}$, $10 \% \mathrm{H}_{2} \mathrm{SO}_{4}$, distilled water, and $0.1 \mathrm{M} \mathrm{NaNO}_{3}$; it was then bubbled into the system to exclude $\mathrm{CO}_{2}$ until the electrode potential was stable. Afterwards, $0.08889 \mathrm{M} \mathrm{HNO}_{3}$ in increments of $0.1 \mathrm{ml}$ was gradually added. When the $\mathrm{pH}$ of the system dropped below 3, a certain amount of $0.100 \mathrm{M}$ $\mathrm{Cu}\left(\mathrm{NO}_{3}\right)_{2}$ was added and $0.01916 M \mathrm{NaOH}$ in $0.1 \mathrm{ml}$ increments was used to backtitrate the suspension up to a $\mathrm{pH}$ of approximately 11 . During the titration period, $\mathrm{N}_{2}$ was bubbled to exclude $\mathrm{CO}_{2}$ and the mixture was stirred magnetically, the temperature being held constant at $25 \pm 0.5^{\circ} \mathrm{C}$. The equilibrium criterion for each addition of the titrant was that the drift in the measured glass electrode potential was lower than $1 \mathrm{mV} / \mathrm{h}$. The equilibrium concentrations of $\mathrm{H}^{+}$ and $\mathrm{Cu}^{2+}$ were respectively calculated from the outputs of the glass electrode and the copper electrode according to equations

$$
E_{\mathrm{H}}=E_{\mathrm{H}}^{0}+59.157 \log \left[\mathrm{H}^{+}\right]
$$

and

$$
E_{\mathrm{Cu}}=E_{\mathrm{Cu}}^{0}+k \log \left[\mathrm{Cu}^{2+}\right] .
$$

$E_{\mathrm{H}}^{0}$ was a constant determined in each titration by an in-situ Gran plot method and then used to calibrate the output of the glass electrode emf (potential $E$ in $\mathrm{mV}$ ) into the $\mathrm{pH}$ value in terms of $\mathrm{H}^{+}$concentration $(5) . E_{\mathrm{Cu}}^{0}$ and $k$ were constants determined from a calibration curve made by the three first outputs of the copper electrode after a known amount of copper was added to the acidic illite suspensions in the three potentiometric titrations with different copper concentrations.

\section{Batch Adsorption Experiments}

Batch adsorption experiments were conducted to individually determine the adsorption isotherms of copper in the illite/water suspensions at constant $\mathrm{pH}$ values $5.45 \pm 0.1$, $5.75 \pm 0.1$, and $6.05 \pm 0.1$.

Each of a group of $100 \mathrm{ml}$ plastic bottles was filled with $15 \mathrm{ml}$ of $10 \mathrm{~g} /$ liter illite stock suspension, $3 \mathrm{ml}$ of $1 \mathrm{M}$ $\mathrm{NaNO}_{3}$, and various amounts of $0.1000 M \mathrm{Cu}\left(\mathrm{NO}_{3}\right)_{2}$ stock solution. Increments of $0.1 M \mathrm{HNO}_{3}$ or $0.1 M \mathrm{NaOH}$ were used to adjust the $\mathrm{pH}$ to a certain value, and distilled water was added to bring the total volume of each sample to 30 $\mathrm{ml}$ with an illite concentration of $5 \mathrm{~g} / \mathrm{liter}$ and an ionic strength of $0.1 \mathrm{M} \mathrm{NaNO}_{3}$. The samples were shaken for 3 $\mathrm{h}$ and left overnight at room temperature. Part of each sample was then filtered through a $0.45 \mu \mathrm{m}$ Millipore membrane, and the filtrate was acidified to a $\mathrm{pH}$ below 2; the remainder was used for the $\mathrm{pH}$ measurement. The copper concentration in the filtrate was measured by a PE3100 flame atomic absorption spectrometer (AAS). The amount of copper adsorbed by illite was determined by the difference between the total concentration of copper added at the beginning of the experiment and the copper concentration in the filtrate measured by AAS after adsorption.

\section{FT-IR Measurements}

The DRIFT spectra of copper hydroxide, copper hydroxylcarbonate, and three different illite samples (pure illite, copper adsorbed illite, and copper adsorbed carbonate-free illite) were recorded.

The following procedures were used to prepare the pure and copper adsorbed illite samples. $3 \mathrm{ml}$ of $10 \mathrm{~g} /$ liter illite and $0.3 \mathrm{ml}$ of $1 \mathrm{M} \mathrm{NaCl}$ were added to a $50 \mathrm{ml}$ beaker. For the copper-adsorbed illite sample, $0.15 \mathrm{ml}$ of $0.1000 \mathrm{M}$ $\mathrm{Cu}\left(\mathrm{NO}_{3}\right)_{2}$ stock solution was also added. Increments of 0.1 $M \mathrm{HCl}$ or $0.1 M \mathrm{NaOH}$ were used to adjust the $\mathrm{pH}$ between 6 and 7, and distilled water was added to bring the total volume of each sample to $30 \mathrm{ml}$ with an illite concentration of $1 \mathrm{~g} /$ liter and an ionic strength of $0.01 \mathrm{M} \mathrm{NaCl}$. After the samples were magnetically stirred at room temperature for $4 \mathrm{~h}, \mathrm{pH}$ values were measured and the suspensions were centrifuged at $20,000 \mathrm{rpm}, 15^{\circ} \mathrm{C}$ for $10 \mathrm{~min}$. The solid part of each sample was dried at $60^{\circ} \mathrm{C}$ and was then used for DRIFT measurements.

The copper adsorbed carbonate-free illite sample was prepared under the bubbling of $\mathrm{N}_{2}$. First, in order to eliminate the carbonate in the illite, an excess of $0.1 \mathrm{M} \mathrm{HCl}$ was added to a $30 \mathrm{ml}$ illite suspension with an illite concentration of 1 $\mathrm{g} /$ liter and an ionic strength of $0.01 \mathrm{M} \mathrm{NaCl}$ until the $\mathrm{pH}$ dropped below 3. After the sample was magnetically stirred for $2 \mathrm{~h}, 0.15 \mathrm{ml}$ of $0.1000 M \mathrm{Cu}\left(\mathrm{NO}_{3}\right)_{2}$ was added and 0.1 $M \mathrm{NaOH}$ was used to bring the $\mathrm{pH}$ of the suspension up to $6-7$. The sample was magnetically stirred at room temperature for another $4 \mathrm{~h}$; then the $\mathrm{pH}$ value was determined, and the solid for DRIFT measurement was obtained as described above.

\section{Data Treatment}

As described in detail in our previous paper (5), for every titration system the $V_{\mathrm{e} 1}$ point in the Gran plot of the hydroxide titration, i.e., the volume of $\mathrm{NaOH}$ added at the acid side equivalence point of the hydroxide titration, was taken as the zero titration point (ZTP). Then for each titration point, the concentration of the total protons added to the system was calculated as

\section{TOTH}

$$
=-\left(V_{\mathrm{b}}-V_{\mathrm{e} 1}\right) C_{\mathrm{b}} /\left(V_{0}+V_{\mathrm{at}}+V_{\mathrm{b}}\right),(\mathrm{mol} / \text { liter })
$$


TABLE 2

Aqueous Copper Speciation in Pure Water Solutions

Formation of soluble species

$$
\begin{aligned}
& \mathrm{Cu}^{2+}+\mathrm{OH}^{-} \rightleftarrows \mathrm{CuOH} \\
& \mathrm{Cu}^{2+}+2 \mathrm{OH}^{-} \rightleftarrows \mathrm{Cu}(\mathrm{OH})_{2} \\
& \mathrm{Cu}^{2+}+3 \mathrm{OH}^{-} \rightleftarrows \mathrm{Cu}(\mathrm{OH})_{3}^{-} \\
& \mathrm{Cu}^{2+}+4 \mathrm{OH}^{-} \rightleftarrows \mathrm{Cu}(\mathrm{OH})_{4}^{2-} \\
& 2 \mathrm{Cu}^{2+}+2 \mathrm{OH}^{-} \rightleftarrows \mathrm{Cu}_{2}(\mathrm{OH})_{2}^{2+}
\end{aligned}
$$

Formation of precipitates

$$
\begin{aligned}
& \mathrm{Cu}^{2+}+2 \mathrm{OH}^{-} \rightleftarrows \mathrm{Cu}(\mathrm{OH})_{2} \\
& \mathrm{Cu}^{2+}+\mathrm{CO}_{3}^{2-} \rightleftarrows \mathrm{CuCO}_{3} \\
& 2 \mathrm{Cu}^{2+}+\mathrm{CO}_{3}^{2-}+2 \mathrm{OH}^{-} \rightleftarrows \mathrm{Cu}_{2}(\mathrm{OH})_{2} \mathrm{CO}_{3} \\
& 3 \mathrm{Cu}^{2+}+2 \mathrm{CO}_{3}^{2-}+2 \mathrm{OH}^{-} \rightleftarrows \mathrm{Cu}_{3}(\mathrm{OH})_{2}\left(\mathrm{CO}_{3}\right)_{2}
\end{aligned}
$$

$$
\begin{aligned}
& \log K=6.3\left(25^{\circ} \mathrm{C}, I=0\right) \\
& \log K=12.8\left(25^{\circ} \mathrm{C}, I=1.0\right) \\
& \log K=14.5\left(25^{\circ} \mathrm{C}, I=1.0\right) \\
& \log K=16.4\left(25^{\circ} \mathrm{C}, I=0\right) \\
& \log K=17.02\left(20^{\circ} \mathrm{C}, I=0.1\right)
\end{aligned}
$$

Note. The constants are taken from ref (6).

${ }^{a}$ Reactions exist only when there are carbonates in the system.

where $C_{\mathrm{b}}$ is the concentration of $\mathrm{NaOH}, V_{\text {at }}$ is the total volume of acid added in the acid titration, and $V_{\mathrm{b}}$ is the volume of $\mathrm{NaOH}$ added in the hydroxide backtitration.

At each titration point, the average number of protons reacted per surface site $(Z)$ was determined by

$$
\begin{aligned}
Z=\left[\mathrm{TOTH}-10^{-\mathrm{pH}}+\right. & \left.10^{-\left(\mathrm{pK}_{\mathrm{w}}-\mathrm{pH}\right)}\right] \\
& \times\left(V_{0}+V_{\text {at }}+V_{\mathrm{b}}\right) /\left(\mathrm{H}_{\mathrm{S}} V_{0}\right)
\end{aligned}
$$

$\mathrm{H}_{\mathrm{S}}$ is the total proton surface site concentration of the illite suspension (Table 1).

\section{Model Calculation}

The intrinsic adsorption constants of copper at the illite surfaces were determined from both the batch adsorption data and the potentiometric titration data by using the computer program FITEQL (version 2.0) (9). For the estimation of constants from the potentiometric titrations, the hydroxide titration data after the calibration of ZTP (TOTH - pH), together with the copper concentration measured by the copper electrode at each $\mathrm{pH}$ value, were input into the data file of the FITEQL program. The FITEQL calculations were performed with different values of the specific capacitance (C) until the best fit was obtained. An indicator for goodness of fit is the overall variance $V_{Y}$, values between 0.1 and 20 being typical of a good fit (9).

The species distribution in the illite/water suspensions was calculated using the computer program SOLGASWATER (10). The related equilibrium constants regarding bulk solution species were taken from Smith and Martell (6), and the constants of surface reactions (as shown in Table 1 and Table 3 ) were obtained from the FITEQL calculations.

\section{RESULTS AND DISCUSSION}

\section{Results of Experiments}

In the potentiometric titration experiments, we examined the adsorption behavior of aqueous illite surfaces by measuring the $\mathrm{pH}$-dependent surface reacted protons using a glass electrode, and the $\mathrm{pH}$-dependent copper adsorption using a cupric ion selective electrode. Fig. 1 shows that the adsorption of copper at the illite surfaces was strongly dependent on $\mathrm{pH}$ values. The adsorption started at about $\mathrm{pH} 4.5$ and increased steeply with the increase of $\mathrm{pH}$. It can be also seen from Fig. 1 that with the increase of the total copper concentration, the $\mathrm{pH}$ adsorption edge shifted to a higher $\mathrm{pH}$ value, which is the same as saying that the adsorption affinity decreased as the copper concentration increased. This may be explained by the fact that the higher surface coverage resulting from the increase of metal concentration raises the activation energy for reaction, thereby making it more difficult for the surface to bind metal ions.

The Z-plots in Fig. 2 display that at the same $\mathrm{pH}$ value, compared with the pure illite suspension, there were more protons released in the illite suspensions with copper. The extra proton release caused by the presence of copper began at about $\mathrm{pH} 4.5$, which corresponds to the $\mathrm{pH}$ value at which copper adsorption started (Fig. 1). This indicates that the uptake of copper causes a deprotonation of surface groups.

The adsorption isotherms of copper at the illite surfaces (Fig. 3 ) show that the copper adsorption exhibited a Langmuir behavior at lower $\mathrm{pH}$ and copper concentrations. The uptake of copper increased exponentially at higher $\mathrm{Cu}$ (II) concentration levels. We attribute this phenomenon to the possibility that copper precipitate forms at higher $\mathrm{pH}$ values and copper concentrations. This will be discussed in detail in another section. 
TABLE 3

Intrinsic Copper-R elated Reaction Constants in the Studied Illite Suspensions $\left(25^{\circ} \mathrm{C}, I=0.1 \mathrm{M}\right)$

(A) Results from potentiometric titrations

FITEQL calculation

\begin{tabular}{|c|c|c|c|c|c|c|c|c|}
\hline \multirow{2}{*}{$\begin{array}{l}\text { TOTCu } \\
(\mathrm{m} M)\end{array}$} & \multirow[b]{2}{*}{$V_{\mathrm{Y}}$} & \multicolumn{2}{|c|}{$\mathrm{SOCu}^{+}$} & \multicolumn{2}{|c|}{$\mathrm{SOCuOH}$} & \multirow{2}{*}{$\begin{array}{c}\mathrm{SOCu}_{2}(\mathrm{OH})_{2}^{+} \\
\log K_{1,2,-3}^{\mathrm{int}}\end{array}$} & \multirow{2}{*}{$\begin{array}{c}\mathrm{SOCu}_{2}(\mathrm{OH})_{3}(\mathrm{sp}) \\
\log K_{\mathrm{SP}}\end{array}$} & \multirow{2}{*}{$\begin{array}{c}\mathrm{Cu}(\mathrm{OH})_{2}(\mathrm{~s}) \\
\log K_{\mathrm{S}}{ }^{b}\end{array}$} \\
\hline & & $\log K_{1,1,-1}^{\mathrm{int}}$ & $\sigma_{\log K}$ & $\log K_{1,1,-2}^{\mathrm{int}}$ & $\sigma_{\log K}$ & & & \\
\hline 0.105 & 45.18 & -3.18 & 0.009 & -8.74 & 0.014 & & & \\
\hline 0.184 & 23.94 & -3.24 & 0.009 & -8.64 & 0.012 & & & \\
\hline 0.544 & 22.75 & -3.06 & 0.015 & -8.15 & 0.016 & -11.8 & -14.0 & \\
\hline mean $\log K$ & & -3.16 & & -8.51 & & -11.8 & -14.0 & 18.48 \\
\hline
\end{tabular}

(B) Results from batch adsorption experiments (FITEQL calculation)

\begin{tabular}{|c|c|c|c|c|c|}
\hline \multirow[b]{2}{*}{$\mathrm{pH}$} & \multirow[b]{2}{*}{$V_{\mathrm{Y}}$} & \multicolumn{2}{|c|}{$\mathrm{SOCu}^{+}$} & \multicolumn{2}{|c|}{$\mathrm{SOCuOH}$} \\
\hline & & $\log K_{1,1,-1}^{\mathrm{int}}$ & $\sigma_{\log K}$ & $\log \mathrm{K}_{1,1,-2}^{\mathrm{int}}$ & $\sigma_{\log K}$ \\
\hline $5.45 \pm 0.1$ & 2.51 & -3.87 & 0.026 & & \\
\hline $5.75 \pm 0.1$ & 36.18 & -4.02 & 0.019 & & \\
\hline $6.05 \pm 0.1$ & 19.94 & -4.30 & 0.035 & -8.58 & 0.024 \\
\hline mean $\log K$ & & -4.06 & & -8.58 & \\
\hline
\end{tabular}

${ }^{a}$ The SOLGASWATER calculation were performed by minimizing $\Sigma\left(\mathrm{TOTH}_{\text {calc. }}-\mathrm{TOTH}_{\text {exp. }}\right)^{2}$ and keeping the earlier calculated surface reaction constants fixed (15), while $\mathrm{TOTH}_{\text {calc. }}$ and $\mathrm{TOTH}_{\text {exp. }}$ are, respectively, the total proton concentrations obtained from the calculation and the experiment (cf. Eq. [4]).

${ }^{b}$ The constant is taken from ref (6).

\section{Surface Reactions in $\mathrm{Cu}^{2+}-$ Illite Systems}

Table 2 is a summary of copper reactions in pure water solutions. In theory, all the copper species listed in Table 2

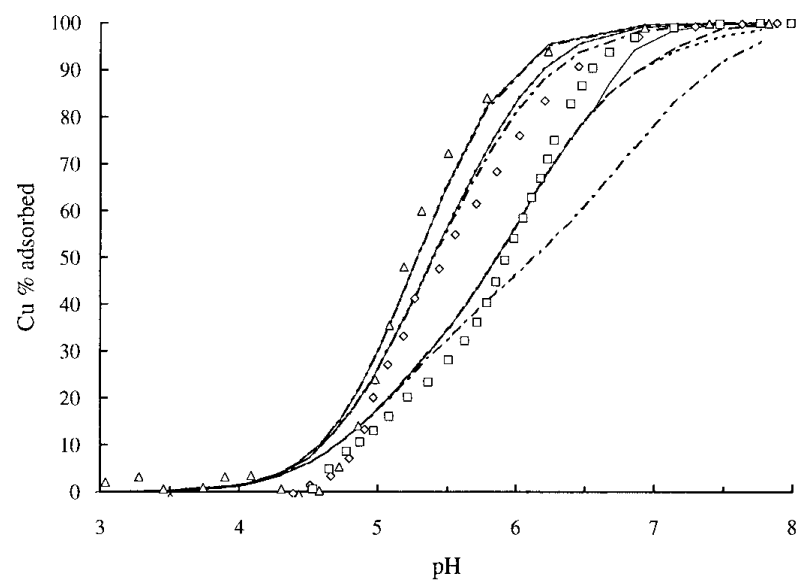

FIG. 1. pH-dependent copper adsorption at aqueous illite surfaces. Points: experimental data. Triangle: $\mathrm{Cu}$ (II) $0.105 \mathrm{mM}$. Diamond: $\mathrm{Cu}$ (II) $0.184 \mathrm{mM}$. Square: $\mathrm{Cu}$ (II) $0.544 \mathrm{mM}$. Lines: model simulations. For each suspension system: - - the formation of surface complexes $\equiv \mathrm{SOCu}^{+}$and $\equiv \mathrm{SO}$ $\mathrm{CuOH}$ was considered; --- the formation of surface complexes $\equiv \mathrm{SOCu}^{+}$, $\equiv \mathrm{SOCuOH}$ and $\equiv \mathrm{SOCu}_{2}(\mathrm{OH})_{2}^{+}$was considered; - - the formation of surface complexes $\equiv \mathrm{SOCu}^{+}, \equiv \mathrm{SOCuOH}, \equiv \mathrm{SOCu}_{2}(\mathrm{OH})_{2}^{+}$and surface precipitate $\equiv \mathrm{SOCu}_{2}(\mathrm{OH})_{3}$ ( $\mathrm{sp}$ ) was considered; - the formation of surface complexes $\equiv \mathrm{SOCu}^{+}, \equiv \mathrm{SOCuOH}, \equiv \mathrm{SOCu}_{2}(\mathrm{OH})_{2}^{+}$and bulk precipitate $\mathrm{Cu}(\mathrm{OH})_{2}$ (s) was considered. can be sorbed at solid surfaces. A general description for the uptake of copper at aqueous illite surfaces, given by the constant capacitance surface complexation model, is

$$
\begin{aligned}
n \equiv \mathrm{SOH} & +m \mathrm{Cu}^{2+}+(p-n) \mathrm{H}_{2} \mathrm{O} \\
& \rightleftarrows(\equiv \mathrm{SO})_{n} \mathrm{Cu}_{m}(\mathrm{OH})_{(p-n)}^{(2 m-p)}+p \mathrm{H}^{+}, K_{n, m,-p}^{\mathrm{int}}
\end{aligned}
$$

where $n, m$, and $p$ are, respectively, the numbers of surface sites, copper ions, and protons involved in the surface reaction. The general expression of the intrinsic adsorption constant, $K_{n, m,-p}^{\text {int }}$, is

$$
\begin{aligned}
& K_{n, m, p}^{\mathrm{int}}=\frac{\left[(\equiv \mathrm{SO})_{n} \mathrm{Cu}_{m}(\mathrm{OH}) \underset{(p-n)}{(2 m-p)}\right]\left[\mathrm{H}^{+}\right]^{p}}{[\equiv \mathrm{SOH}]^{n}\left[\mathrm{Cu}^{2+}\right]^{m}} \\
& \quad \times \exp \left(-(2 m-p) F \Psi_{0} / R T\right),
\end{aligned}
$$

where $F$ is the Faraday constant $\left(C \mathrm{~mol}^{-1}\right), \Psi_{0}$ is the surface potential $(\mathrm{V}), R$ is the molar gas constant $\left(\mathrm{J} \mathrm{mol}^{-1} \mathrm{~K}^{-1}\right)$, and $T$ is the absolute temperature $(\mathrm{K})$.

Because the experimental data obtained from macroscopic experiments, such as potentiometric titrations and batch adsorptions, can only provide indirect evidence of what happens at the solid/water interface, we have to make reasonable assumptions regarding the surface adsorption species when simulating the reactions in metal ion-solid suspensions by adsorption models $(11-13)$. Our principle for se- 
lecting surface species is to start with simple, chemically reasonable species and to add more complicated ones only when necessary to fit the experimental data. The goal is to fit all the experimental data with a minimum number of surface species. On the basis of this principle, we established the copper-illite interaction model for the studied illite suspensions.

\section{Copper-Illite Interaction Model}

In the study of the heavy metal adsorption at the surfaces of kaolinite and montmorillonite (1-3), a combined ion exchange-surface complexation model was used to illustrate their adsorption behaviors. However, the study of the adsorption of trace metals $\mathrm{Cu}$ (II), $\mathrm{Zn}$ (II), $\mathrm{Co}$ (II), and $\mathrm{Cd}$ (II) on kaolinite as a function of the supporting electrolyte concentrations (3) showed that the uptake of heavy metals by the permanent negatively charged surface sites - a process that might be due to ion exchange reaction-was dramatically reduced by the increase of the electrolyte concentration. There was no evidence of this reaction at a level of $0.1 \mathrm{M}$ of supporting electrolyte in their experiments. Moreover, an X-ray absorption spectroscopy (XAS) study of the sorption of metal ion $\mathrm{Co}$ (II) on smectite-clay minerals (14) showed that with the increase of $\mathrm{pH}$ and background electrolyte concentration, Co(II) was increasingly excluded from the interlayer permanent charge sites, which formed outer sphere

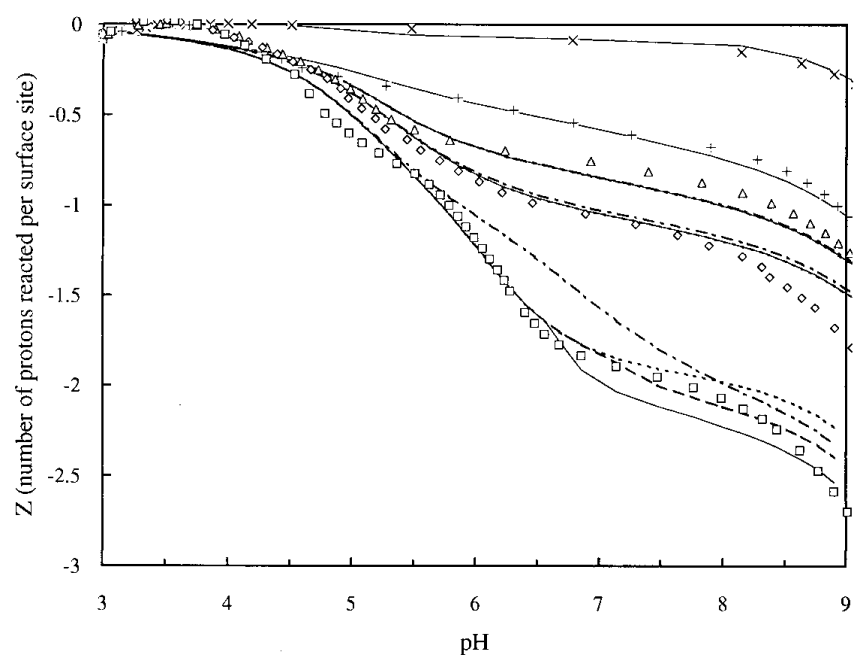

FIG. 2. pH-dependent surface reacted protons per surface site in the $\mathrm{Cu}(\mathrm{II})$-illite suspensions. Points: experimental data, $\times$, supernatant blank titration; +, pure illite suspension. Triangles: $\mathrm{Cu}$ (II) $0.105 \mathrm{~m} M$. Diamonds: $\mathrm{Cu}$ (II) $0.184 \mathrm{~m} M$. Squares: $\mathrm{Cu}$ (II) $0.544 \mathrm{~m} M$. Lines: model simulations. For each suspension system with $\mathrm{Cu}(\mathrm{II})$ : - - - the formation of surface complexes $\equiv \mathrm{SOCu}^{+}$and $\equiv \mathrm{SOCuOH}$ was considered; --- the formation of surface complexes $\equiv \mathrm{SOCu}^{+}$, $\equiv \mathrm{SOCuOH}$ and $\equiv \mathrm{SOCu}_{2}(\mathrm{OH})_{2}^{+}$was considered; - - the formation of surface complexes $\equiv \mathrm{SOCu}^{+}, \equiv \mathrm{SO}$ $\mathrm{CuOH}, \equiv \mathrm{SOCu}_{2}(\mathrm{OH})_{2}^{+}$and surface precipitate $\equiv \mathrm{SOCu}_{2}(\mathrm{OH})_{3}(\mathrm{sp})$ was considered; - the formation of surface complexes $\equiv \mathrm{SOCu}^{+}, \equiv \mathrm{SO}$ $\mathrm{CuOH}, \equiv \mathrm{SOCu}_{2}(\mathrm{OH})_{2}^{+}$and bulk precipitate $\mathrm{Cu}(\mathrm{OH})_{2}(\mathrm{~s})$ was considered. surface complexes with $\mathrm{Co}$ (II) at low $\mathrm{pH}$ and background electrolyte concentrations, and formed complexes with external surface hydroxyl sites. Given these facts, we considered only the behavior of the surface hydroxyl groups ( $\equiv \mathrm{SOH}$ ) in modeling the interaction between $\mathrm{Cu}^{2+}$ and the illite surfaces since we used very high background electrolyte concentration $\left(0.1 \mathrm{MNaNO}_{3}\right)$ in our work.

(1) Carbonate-free illite suspensions. Since carbonates were eliminated by the addition of acid during our potentiometric titrations (5), the copper-illite interaction model established on the analysis of the hydroxide backtitration data is only suitable for carbonate-free illite suspensions. In order to estimate the intrinsic surface reaction constants, the hydroxide titration data of each studied system were modeled separately using the FITEQL program (the SOLGASWATER program was used in part of the calculations of the system with $0.544 \mathrm{mM} \mathrm{Cu}{ }^{2+}$ ) within the framework of the constant capacitance model. During the calculation, the characteristic parameters of the illite surfaces and the supernatant blank system (Table 1) were incorporated into the data file and the copper-related surface reactions were chosen according to the principle introduced above. From the results of the model calculation, we assumed that the uptake of copper in the carbonate-free illite suspensions can be described by the surface adsorption reactions:

$$
\begin{gathered}
\equiv \mathrm{SOH}+\mathrm{Cu}^{2+} \rightleftarrows \equiv \mathrm{SOCu}^{+}+\mathrm{H}^{+}, \quad K_{1,1,-1}^{\text {int }} \\
\equiv \mathrm{SOH}+\mathrm{Cu}^{2+}+\mathrm{H}_{2} \mathrm{O} \rightleftarrows \equiv \mathrm{SOCuOH}+2 \mathrm{H}^{+}, \quad K_{1,1,-2}^{\text {int }} \\
\equiv \mathrm{SOH}+2 \mathrm{Cu}^{2+}+2 \mathrm{H}_{2} \mathrm{O} \\
\rightleftarrows \equiv \mathrm{SOCu}_{2}(\mathrm{OH})_{2}^{+}+3 \mathrm{H}^{+}, \quad K_{1,2,-3}^{\text {int }}
\end{gathered}
$$

followed by the formation of precipitate, either as bulk precipitate,

$$
\mathrm{Cu}^{2+}+2 \mathrm{OH}^{-} \rightleftarrows \mathrm{Cu}(\mathrm{OH})_{2}(\mathrm{~s}),
$$

(see Table 2) $K_{\mathrm{S}}$

or as surface precipitate,

$$
\begin{aligned}
& \equiv \mathrm{SOH}+2 \mathrm{Cu}^{2+} \\
& \quad+3 \mathrm{H}_{2} \mathrm{O} \rightleftharpoons \equiv \mathrm{SOCu}_{2}(\mathrm{OH})_{3}(\mathrm{sp})+4 \mathrm{H}^{+} . \quad K_{\mathrm{SP}}
\end{aligned}
$$

The best-fitted intrinsic constants for the corresponding reactions in three different illite suspensions are summarized in Table 3a. The model simulations of the experimental data using the mean value of the constant for each reaction are plotted in Fig. 1 (pH-dependent copper adsorption) and Fig. 2 ( $\mathrm{pH}$-dependent surface-reacted protons).

Figs. 1 and 2 show that the uptake of copper in illite suspensions with relatively lower copper concentrations $(0.105$ and $0.184 \mathrm{mM} \mathrm{Cu}^{2+}$ ) can be adequately explained by the surface 


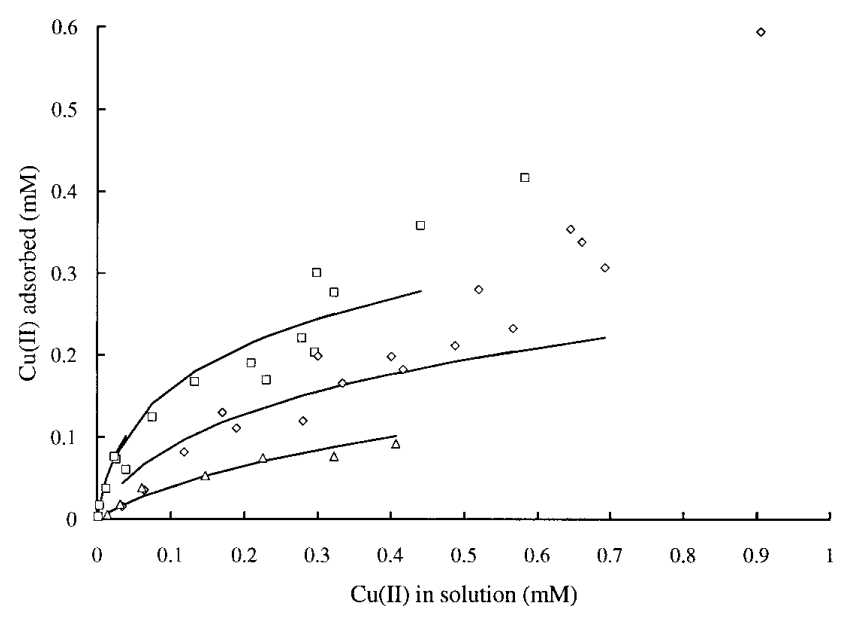

FIG. 3. Adsorption isotherms of $\mathrm{Cu}$ (II) at the illite surfaces. Points: experimental data. Triangles: $\mathrm{pH} 5.45 \pm 0.1$. Diamonds: $\mathrm{pH} 5.75 \pm 0.1$. Squares: $\mathrm{pH} 6.05 \pm 0.1$. Lines: model simulations in which surface reactions for forming $\equiv \mathrm{SOCu}^{+}$and $\equiv \mathrm{SOCuOH}$ were included. Note: The $\mathrm{pH}$ values in the adsorption isotherms are given in terms of $\mathrm{H}^{+}$concentrations after the calibration of activity coefficient by using Debye-Hückel theory in order to make them comparable with the expression of $\mathrm{pH}$ in our potentiometric titrations.

adsorption reactions (Eqs. [8] and [9]) which form simple mononuclear copper surface complexes $\left(\equiv \mathrm{SOCu}^{+}\right.$and $\equiv \mathrm{SOCuOH})$. The inclusion of the surface adsorption of multinuclear copper species $\left(\mathrm{Cu}_{2}(\mathrm{OH})_{2}^{2+}\right)($ Eq. [10]) and the formation of precipitate (Eqs. [10] or [11]) into the copperillite interaction model made little difference in fitting the experimental data. But in the case of the illite suspension with a higher copper concentration $\left(0.544 \mathrm{mM} \mathrm{Cu}{ }^{2+}\right)$, the surface adsorption of mononuclear copper species (Eqs. [8] and [9]) can only explain the experimental data up to a $\mathrm{pH}$ of about 5.8 (Fig. 2) and $40 \%$ of copper uptake (Fig. 1). The inclusion of the formation of multinuclear copper surface complex $\left(\equiv \mathrm{SOCu}_{2}(\mathrm{OH})_{2}^{+}\right)$and copper precipitate $\left(\mathrm{Cu}(\mathrm{OH})_{2}(\mathrm{~s})\right.$ or $\left.\equiv \mathrm{SOCu}_{2}(\mathrm{OH})_{3}(\mathrm{sp})\right)$ greatly improved the description of the experimental data. In addition, these experimental results and model simulations also indicate that not all the surface proton sites were copper active because copper precipitate had already formed even when the total copper concentration was only $0.544 \mathrm{~m} M$, which was still lower than the surface proton site concentration of illite $(0.642 \mathrm{~m} M$, ref. Table 1$)$.

In applying surface complexation models to illustrate the adsorption of metal ions at aqueous solid surfaces, usually only mononuclear surface complexes are considered in the model simulations $(1,2,13,16,17)$. Our experimental data provide indirect evidence for the adsorption of multinuclear copper species at the illite surfaces. The model descriptions of the adsorption behavior fit much better with the experimental data after assuming the formation of multinuclear copper complex at higher copper concentrations (Figs. 1 and 2 ). This assumption is supported by an analysis of aqueous speciation of $\mathrm{Cu}$ (II) in pure water solutions (see Fig. 4), which indicates that the ratio of the concentrations of the multinuclear copper species $\left(\mathrm{Cu}_{2}(\mathrm{OH})_{2}^{+}\right)$and the monohydroxyl copper species $\left(\mathrm{CuOH}^{+}\right)$increases as the total copper concentration increases in the system. In other words, it indicates that $\mathrm{Cu}_{2}(\mathrm{OH})_{2}^{+}$becomes more prevalent with an increase in total copper concentration. This assumption is further supported by the X-ray absorption spectroscopy (XAS) study of $\mathrm{Cu}$ (II) adsorption on the surface of mica, which has the same structure and composition as illite (4). The XAS study provides direct evidence for the copper species adsorbed on the mica surfaces being similar to those found in copper hydroxide, plancheite and shattuckite, which are doubly oxygen-bridged in "ribbons." The formation of multinuclear surface complexes of other heavy metal ions, e.g., $\mathrm{Co}$ (II), on the surfaces of clay minerals kaolinite and smectite has also been demonstrated by X-ray absorption spectroscopy studies $(14,18,19)$. Finally, the copper speciation diagrams in the illite suspensions (Fig. 5) demonstrate the significance of the multinuclear copper surface complex and copper precipitate in systems with higher $\mathrm{Cu}$ (II) concentrations. As shown in Figs. 5a and 5b, for the systems with relatively lower total copper concentrations, $\equiv \mathrm{SOCu}^{+}$ is always the dominant surface species and no copper precipitation occurs within the entire $\mathrm{pH}$ range of copper uptake ( $\mathrm{pH} \mathrm{4-7).} \mathrm{However,} \mathrm{in} \mathrm{the} \mathrm{system} \mathrm{with} \mathrm{higher} \mathrm{copper} \mathrm{con-}$ centrations (Figs. 5c and 5d), $\equiv \mathrm{SOCu}^{+}$is only dominant until a $\mathrm{pH}$ of approximately 6.2; after this point, $\equiv \mathrm{SOCu}_{2}(\mathrm{OH})_{2}^{+}$becomes prevalent and copper precipitation becomes significant at $\mathrm{pH}$ levels close to 7 .

With regard to the precipitation in copper-illite suspensions, there are two possibilities: it can form as either bulk precipitate (Eq. [11]) or surface precipitate (Eq. [12]). Although many spectroscopic studies, e.g., electron spin resonance (ESR) (20), high-resolution transmission electron microscopy (HRTEM) (21) and X-ray absorption spectroscopy $(19,22)$, have provided direct evidence for the surface precipitation of cations on surfaces of oxides, carbonates and clay minerals, there is still no commonly accepted method to include the surface precipitation into model calculations so as to simulate the adsorption behavior in metal ion-solid suspensions. In 1985, Farley et al. (13, 23, 24) incorporated a surface precipitation model into the surface complexation model to describe the transition from adsorption to surface precipitation of cations on metal oxides. This model was later applied to carbonate systems by Comans and Middelburg (25). However, in their stoichiometry matrix of the equilibrium problems, no surface site was considered with respect to the term of surface precipitation, and so surface precipitation was not handled differently than bulk precipitation in their model calculations.

Since it was impossible to determine from our experiments whether surface precipitate or bulk precipitate was formed, we tested both possibilities separately in our model to de- 

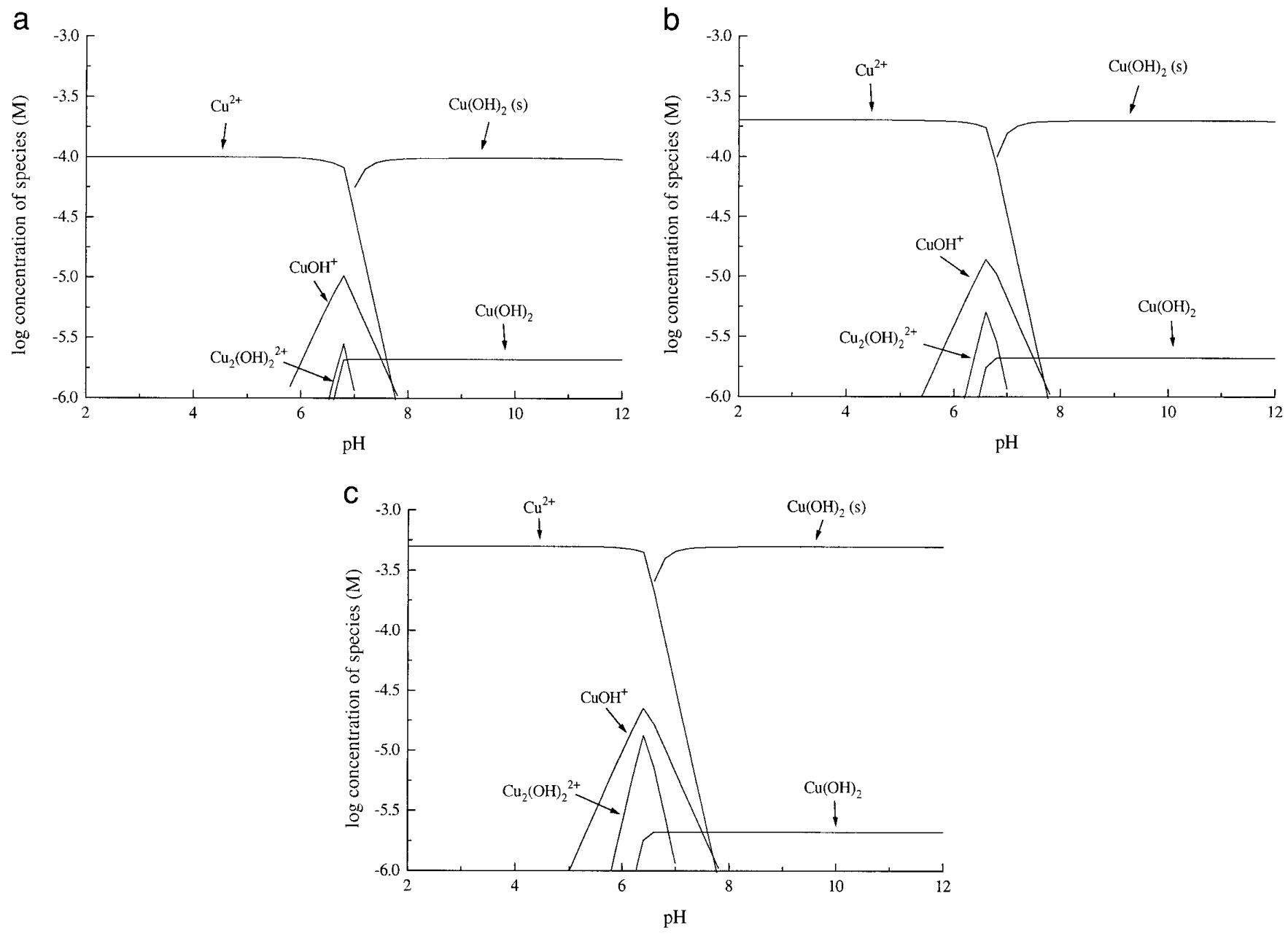

FIG. 4. Aqueous speciation of copper in pure water solutions a. $\mathrm{Cu}(\mathrm{II})=0.100 \mathrm{~m} M$. b. $\mathrm{Cu}$ (II) $=0.200 \mathrm{~m} M$. c. $\mathrm{Cu}$ (II) $=0.500 \mathrm{~m} M$.

scribe the uptake of copper in the illite suspensions. In the model calculations using the SOLGASWATER program, we distinguished surface precipitation from bulk precipitation in the following way. The surface site was included into the stoichiometry matrix to describe the precipitate when surface precipitation was tested, while no surface site was included when bulk precipitation was tested ( see Table 4). From Figs. 1 and 2 , we can see that both alternatives give fairly good results in fitting the experimental data. But the model incorporating bulk precipitation fits better to the $\mathrm{pH}$-dependent adsorption data (Fig. 1) and the model incorporating surface precipitation fits better to the $\mathrm{pH}$-dependent surface reacted proton change (Fig. 2). We do not have a good explanation for this phenomenon. Further experiments to get direct information of what happens on the solid surface and more model calculation tests are needed to solve this problem.

(2) Illite suspensions containing carbonates. Using the same method for handling the potentiometric titration data, we obtained the intrinsic surface adsorption constants (Table 3b) from the batch adsorption experiments, during which the carbonates were not eliminated from the illite samples.

When compared, the intrinsic constants derived from the batch adsorption data were found to be weaker than those for the same surface reactions obtained from the titrations. This can be explained as follows. First, for the batch adsorption experiments, the copper concentration remaining in the solution phase was determined by the AAS analysis, which measures all the soluble copper species; in contrast, for the potentiometric titrations, the copper concentration in solution was determined by a copper electrode, which is only sensitive to free copper ions $\left(\mathrm{Cu}^{2+}\right)$. Secondly, the solid and solution phases in the batch adsorption experiments were separated by filtering the sample through a $0.45 \mu \mathrm{m}$ Millipore membrane; therefore, the copper adsorbed on the particles smaller than $0.45 \mu \mathrm{m}$ was also measured by the AAS as part of the concentration in the solution phase. For these two reasons, in the systems with the same copper and illite composi- 

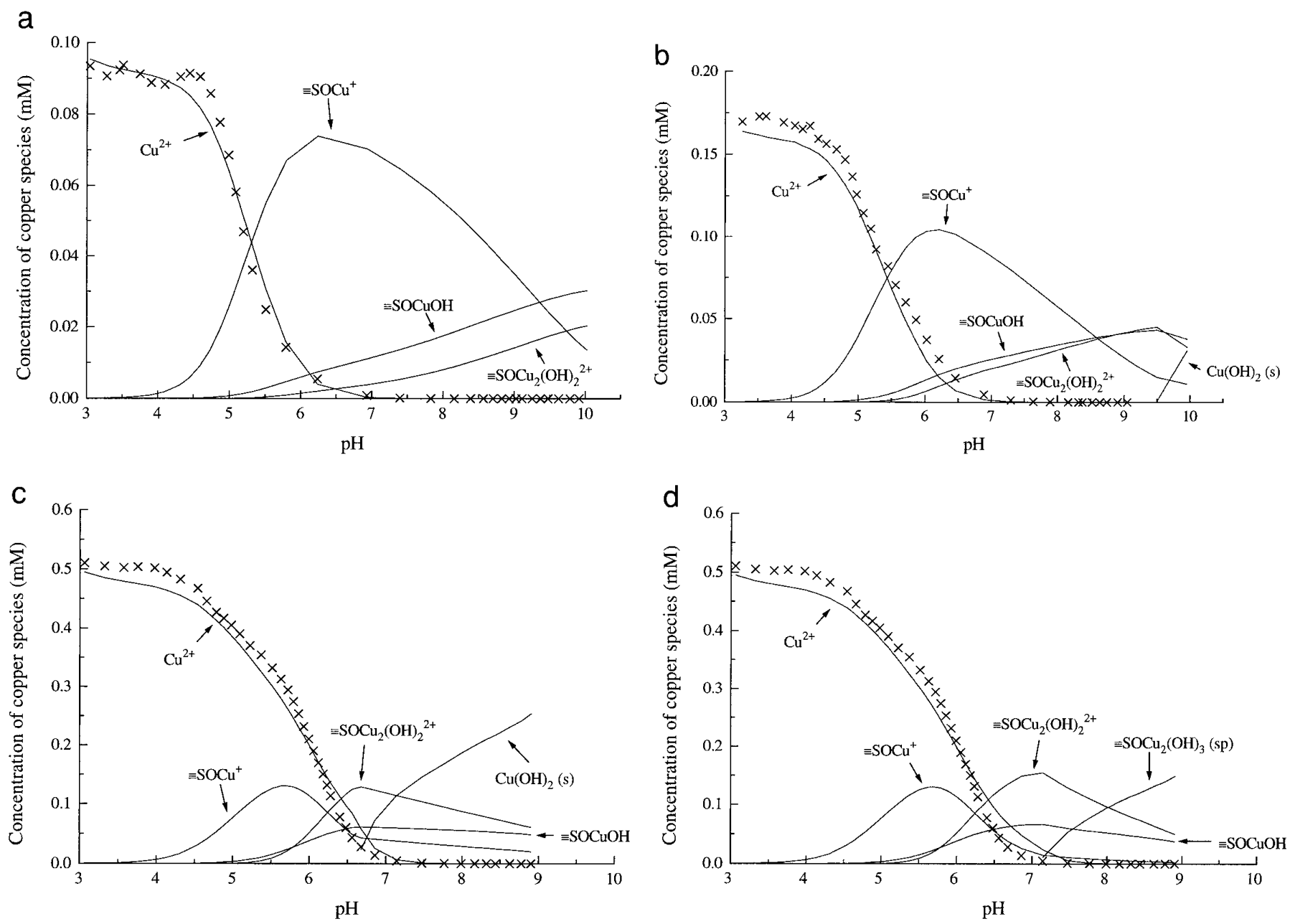

FIG. 5. Speciation diagrams of copper species in the illite suspensions. Points: experimental data; Lines: model calculations using the constants in Tables 1-3. a. $0.105 \mathrm{~m} M \mathrm{Cu}$ (II). b. $0.184 \mathrm{~m} M \mathrm{Cu}$ (II). $c, d$. $0.544 \mathrm{~m} M \mathrm{Cu}$ (II). Note: In the model calculations of Fig. 5a-c, bulk precipitation were considered; in the model calculation of Fig. 5d, surface precipitation was considered.

tions, the unadsorbed copper concentration determined by the AAS analysis in the batch experiments is higher than that determined by the copper electrode in the titration experiments. This resulted in weaker adsorption constants being estimated from the former experiments than those derived from the latter.

The calculated adsorption isotherms using the mean value of the constants obtained from the batch experiments (Table $3 \mathrm{~b}$ ) fit very well to the experimental data at lower $\mathrm{pH}$ and copper concentrations (Fig. 3), which means the uptake of copper in these conditions can be represented by the formation of surface species $\equiv \mathrm{SOCu}^{+}$and $\equiv \mathrm{SOCuOH}$. At higher copper concentration levels, there was an exponential increase of the uptake of copper by the illite surfaces, a trend that might be attributed to the formation of copper precipitates. The speciation diagrams of copper in the carbonate-free illite suspensions (Fig. 5) show that no copper hydroxide precipitate formed before $\mathrm{pH} 6.8$ (when the total
$\mathrm{Cu}(\mathrm{II})$ is $0.544 \mathrm{mM}$ ), which implies that the precipitate formed at the $\mathrm{pH}$ in the batch experiments (the highest $\mathrm{pH}$ was $6.05 \pm 0.1$ ) could not have been copper hydroxide precipitate. Since carbonates existed in the illite samples used in these experiments, we suppose that the behavior at higher copper concentrations in Fig. 3 is due to the formation of copper hydroxylcarbonates. This assumption was supported by the information in the FT-IR spectra (Fig. 6) of pure chemicals and the illites (with and without carbonates) after copper adsorption.

In Fig. 6, it is apparent that the positions of $\mathrm{O}-\mathrm{H}$ stretching vibration peaks in the copper adsorbed illite (with carbonates) ( see Fig. 6c, 3451 and $3361-3322 \mathrm{~cm}^{-1}$ ) are similar to those in copper hydroxylcarbonate (see Fig. 6e, 3411 and $3325 \mathrm{~cm}^{-1}$, very different from the broad peak at 3418 $\mathrm{cm}^{-1}$ of copper hydroxide in Fig. 6d). This demonstrates that copper hydroxylcarbonate exists at $\mathrm{pH} 6.2$ (lower than the $\mathrm{pH}$ at which copper hydroxide precipitation starts) in 
TABLE 4

Stoichiometry Matrix of Reactions in the Copper - Illite Suspensions

Components

\begin{tabular}{|c|c|c|c|c|c|c|c|c|}
\hline \multirow[b]{2}{*}{ Species } & \multicolumn{6}{|c|}{ Components } & \multirow[b]{2}{*}{$\log K$} & \multirow[b]{2}{*}{ References } \\
\hline & $\mathrm{H}^{+}$ & $\mathrm{Si}(\mathrm{OH})_{4}$ & $\mathrm{Al}^{3+}$ & $\mathrm{Cu}^{2+}$ & $\equiv \mathrm{SOH}$ & $\exp (-e \Psi / k T)$ & & \\
\hline $\mathrm{H}^{+}$ & 1 & 0 & 0 & 0 & 0 & 0 & 0 & \\
\hline $\mathrm{OH}^{-}$ & -1 & 0 & 0 & 0 & 0 & 0 & -13.8 & \\
\hline $\mathrm{Si}(\mathrm{OH})_{4}$ & 0 & 1 & 0 & 0 & 0 & 0 & 0 & \\
\hline $\mathrm{SiO}(\mathrm{OH})_{3}^{-}$ & -1 & 1 & 0 & 0 & 0 & 0 & -9.46 & ref $(6)$ \\
\hline $\mathrm{SiO}_{2}(\mathrm{OH})_{2}^{2-}$ & -2 & 1 & 0 & 0 & 0 & 0 & -22.02 & $\operatorname{ref}(6)$ \\
\hline $\mathrm{Al}^{3+}$ & 0 & 0 & 1 & 0 & 0 & 0 & 0 & \\
\hline $\mathrm{AlOH}^{2+}$ & -1 & 0 & 1 & 0 & 0 & 0 & -5.52 & \\
\hline $\mathrm{Al}(\mathrm{OH})_{2}^{+}$ & -2 & 0 & 1 & 0 & 0 & 0 & -10.4 & \\
\hline $\mathrm{Cu}^{2+}$ & 0 & 0 & 0 & 1 & 0 & 0 & 0 & \\
\hline $\mathrm{CuOH}^{+}$ & -1 & 0 & 0 & 1 & 0 & 0 & -7.7 & $\operatorname{ref}(6)$ \\
\hline $\mathrm{Cu}(\mathrm{OH})_{2}$ & -2 & 0 & 0 & 1 & 0 & 0 & -15.2 & ref (6) \\
\hline $\mathrm{Cu}(\mathrm{OH})_{3}^{-}$ & -3 & 0 & 0 & 1 & 0 & 0 & -27.5 & $\operatorname{ref}(6)$ \\
\hline $\mathrm{Cu}(\mathrm{OH})_{4}^{2-}$ & -4 & 0 & 0 & 1 & 0 & 0 & -39.6 & $\operatorname{ref}(6)$ \\
\hline $\mathrm{Cu}_{2}(\mathrm{OH})_{2}^{2+}$ & -2 & 0 & 0 & 2 & 0 & 0 & -10.98 & $\operatorname{ref}(6)$ \\
\hline$\equiv \mathrm{SOH}$ & 0 & 0 & 0 & 0 & 1 & 0 & 0 & \\
\hline$\equiv \mathrm{SO}^{-}$ & -1 & 0 & 0 & 1 & 1 & -1 & -4.23 & Table 1 \\
\hline$\equiv \mathrm{SOCu}^{+}$ & -1 & 0 & 0 & 1 & 1 & 1 & -3.16 & Table 3 \\
\hline$\equiv \mathrm{SOCuOH}$ & -2 & 0 & 0 & 1 & 1 & 0 & -8.51 & Table 3 \\
\hline$\equiv \mathrm{SOCu}_{2}(\mathrm{OH})_{2}^{+}$ & -3 & 0 & 0 & 2 & 1 & 1 & -11.8 & Table 3 \\
\hline $\mathrm{Cu}(\mathrm{OH})_{2}(\mathrm{~s})^{a}$ & -2 & 0 & 0 & 1 & 0 & 0 & -9.12 & ref (6) \\
\hline$\equiv \mathrm{SOCu}_{2}(\mathrm{OH})_{3}(\mathrm{sp})^{b}$ & -4 & 0 & 0 & 2 & 1 & 0 & -14.0 & Table 3 \\
\hline
\end{tabular}

${ }^{a}$ Matrix was used when bulk precipitation was tested.

${ }^{b}$ Matrix was used when surface precipitation was tested.

the copper adsorbed illite. The shifts of these peaks and the replacement of the single peak at $3325 \mathrm{~cm}^{-1}$ by the doublet peaks (3361 and $3322 \mathrm{~cm}^{-1}$ ) in the copper adsorbed illite sample might be due to the influence of the illite structure, which is also an indication of copper-illite coordination. In contrast, the peaks of $\mathrm{O}-\mathrm{H}$ stretching vibration in $\mathrm{Cu}_{2}$ $(\mathrm{OH})_{2} \mathrm{CO}_{3}$ do not show up in the spectrum of the copper adsorbed carbonate-free illite, which gives us more evidence that carbonates can be eliminated by the addition of acid during the potentiometric titrations.

From the above experimental results and analysis, we suggest that the uptake of copper in the illite suspensions containing carbonates can be described by the surface adsorption reactions (Eqs. [8] and [9]):

$$
\equiv \mathrm{SOH}+\mathrm{Cu}^{2+} \rightleftarrows \equiv \mathrm{SOCu}^{+}+\mathrm{H}^{+} \quad K_{1,1,-1}^{\mathrm{int}}
$$

and

$$
\equiv \mathrm{SOH}+\mathrm{Cu}^{2+}+\mathrm{H}_{2} \mathrm{O} \rightleftarrows \equiv \mathrm{SOCuOH}+2 \mathrm{H}^{+}, \quad K_{1,1,-2}^{\text {int }}
$$

followed by the formation of copper hydroxylcarbonate precipitate ( see Table 2),

$$
2 \mathrm{Cu}^{2+}+2 \mathrm{OH}^{-}+\mathrm{CO}_{3}^{2-} \rightleftarrows \mathrm{Cu}_{2}(\mathrm{OH})_{2} \mathrm{CO}_{3}(\mathrm{~s}) .
$$

\section{CONCLUSIONS}

The study of copper adsorption at the aqueous illite surfaces by potentiometric titrations, batch adsorption experiments, and FT-IR measurements leads us to the following conclusions.

(1) The adsorption of copper at the illite surfaces is strongly dependent on $\mathrm{pH}$, and the uptake of copper causes a deprotonation of surface groups.

(2) With the increase of the total copper concentration, the $\mathrm{pH}$ adsorption edge shifts to a higher $\mathrm{pH}$ value. The adsorption isotherm of copper at the illite surfaces exhibits a Langmuir behavior at lower $\mathrm{pH}$ and copper concentrations.

(3) The uptake of copper in the carbonate-free illite suspensions can be explained by the formation of surface complexes, $\equiv \mathrm{SOCu}^{+}, \equiv \mathrm{SOCuOH}$ and $\equiv \mathrm{SOCu}_{2}(\mathrm{OH})_{2}^{+}$, followed by the formation of a bulk precipitate, $\mathrm{Cu}(\mathrm{OH})_{2}(\mathrm{~s})$, or a surface precipitate, $\equiv \mathrm{SOCu}_{2}(\mathrm{OH})_{3}(\mathrm{sp})$, with an increase in copper concentration and $\mathrm{pH}$.

(4) The copper-illite interaction model in the illite suspensions containing carbonates can be represented by the formation of surface complexes, $\equiv \mathrm{SOCu}^{+}$and $\equiv \mathrm{SO}$ $\mathrm{CuOH}$, followed by the formation of a copper hydroxylcarbonate precipitate, $\mathrm{Cu}_{2}(\mathrm{OH})_{2} \mathrm{CO}_{3}(\mathrm{~s})$, with an increase in copper concentration and $\mathrm{pH}$. 


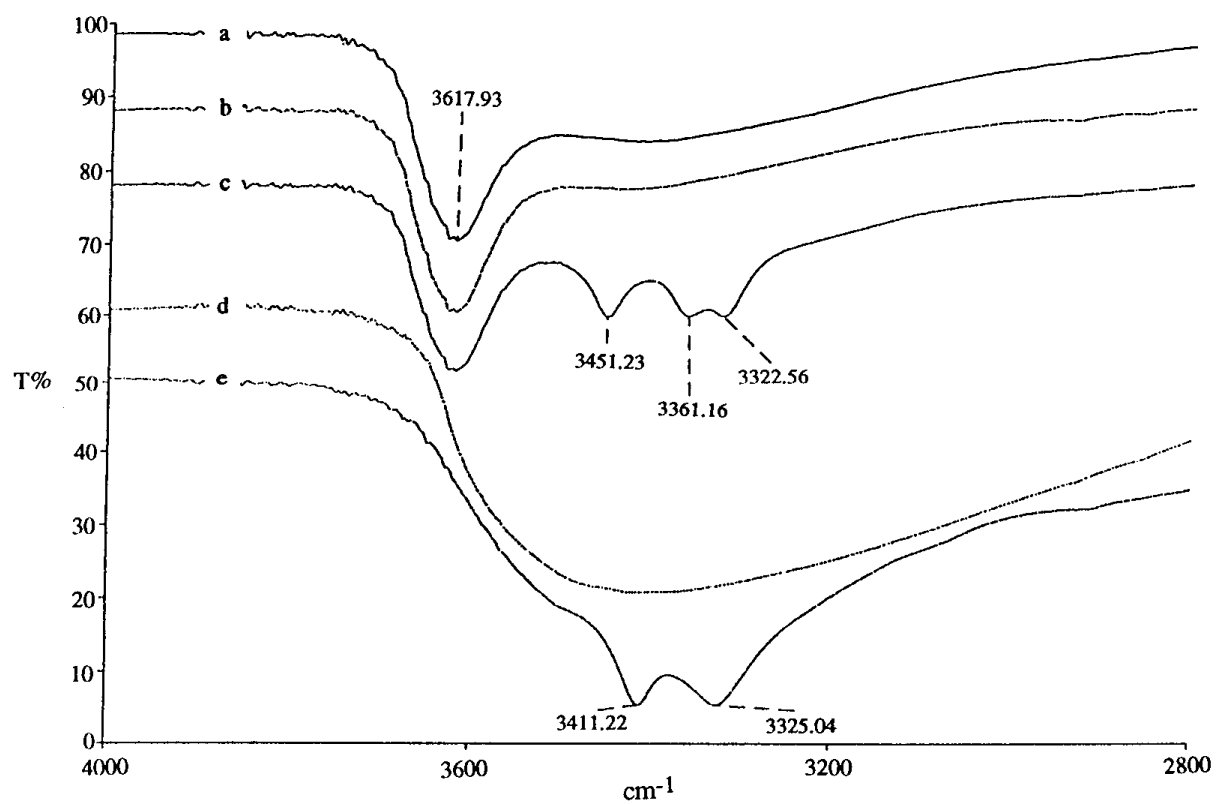

FIG. 6. FT-IR spectra for (a) pure illite, $\mathrm{pH}$ 6.80; (b) copper-adsorbed illite (carbonate-free), pH 6.19; (c) copper-adsorbed illite (containing carbonate), $\mathrm{pH} 6.18$; (d) $\mathrm{Cu}(\mathrm{OH})_{2}$; and (e) $\mathrm{Cu}_{2}(\mathrm{OH})_{2} \mathrm{CO}_{3}$.

\section{ACK NOWLEDGMENTS}

We thank Professor Chen Kaihui of the Geology Institute, Academia Sinica, for providing us with illite samples. We also thank Dr. Lars Gunneriusson of the Division of Inorganic Chemistry, Luleå University of Technology, for his valuable comments and suggestions on earlier drafts of this paper. Finally, Ms. Du expresses thanks to Luleå University of Technology for providing research funds for this project.

\section{REFERENCES}

1. Schindler, P. W., Liechti, P., and Westall, J. C., Neth. J. Agric. Sci. 35, 219 (1987).

2. Stadler, M., and Schindler, P. W., Clays Clay Min. 41, 556 (1993).

3. Spark, K. M., Wells, J. D., and Johnson, B. B., Eur. J. Soil Sci. 46(12), 633 (1995).

4. Farquhar, M. L., Charnock, J. M., England, K. E. R., and Vaughan, D. J., J. Colloid Interface Sci. 177, 561 (1996).

5. Du, Q., Sun, Z., Forsling, W., and Tang, H., J. Colloid Interface Sci. 187, 221 (1997).

6. Smith, R. M., and Martell, A. E., 'Critical stability constants. Volume 4: Inorganic complexes.' Plenum Press, New York, 1976.

7. Ginstrup, O., Chem. Instrum. 4, 141 (1973).

8. Forsling, W., Hietanen, S., and Sillen, L. G., Acta Chem. Scand. 6, 901 (1952).

9. Westall, J. C., "'FITEQL: a program for the determination of chemical equilibrium constants from experimental data.' Rep. 82-01. Department of Chemistry, Oregon State University, Corvallis, OR, 1982.

10. Eriksson, G. A., Anal. Chim. Acta 112, 375 (1979).
11. Van Riemsdijk, W. H., De Wit, J. C., Koppal, L. K., et al., J. Colloid Interface Sci. 116, 511 (1987).

12. Hayes, K. F., and Leckie, J. O., J. Colloid Interface Sci. 115, 564 (1978).

13. Dzombak, D. A., and Morel, F. M. M., "Surface complexation modeling, hydrous ferric oxide.' John Wiley, New York, 1990.

14. Papelis, C., and Hayes, K. F., Colloids Surf. A: Physicochem. Eng. Aspects 107, 89 (1996).

15. Gunneriusson, L., "Aqueous speciation and surface complexation to goethite $(\alpha-\mathrm{FeOOH})$, of divalent mercury, lead and cadmium.'” Ph.D. Thesis, Department of Inorganic Chemistry, University of Umeå, Sweden, 1993.

16. Hohl, H., and Stumm, W., J. Colloid Interface Sci. 55, 281 (1976).

17. Davis, J. A., and Leckie, J. O., J. Colloid Interface Sci. 67, 90 (1978).

18. Chisholm-Brause, C. J., O’Day, P. A., Brown, G. E., Jr., and Parks, G. A., Nature 348, 528 (1990).

19. O’Day, P. A., Brown, G. E., Jr., and Parks, G. A., J. Colloid Interface Sci. 165, 269 (1994).

20. Wersin, P., Charlet, L., Karthein, R., and Stumm, W., Geochim. Cosmochim. Acta 53, 2787 (1989).

21. Fendorf, S. E., Sparks, D. L., Fendorf, M., and Gronsky, R., J. Colloid Interface Sci. 148, 295 (1992).

22. Charlet, L., and Manceau, A. A., J. Colloid Interface Sci. 148, 443 (1992).

23. Farley, K. J., Dzombak, D. A., and Morel, F. M. M., J. Colloid Interface Sci. 106, 226 (1985).

24. Dzombak, D. A., and Morel, F. M. M., J. Colloid Interface Sci. 112, 588 (1986).

25. Comans, R. N. J., and Middelburg, J. J., Geochim. Cosmochim. Acta 51, 2587 (1987). 